\title{
XII National Congress of Experimental Surgery, IX Forum of Scientific Initiation, Workshop on Organ Transplantation.
}

\author{
XII Congresso Nacional de Cirurgia Experimental, IX Fórum de Iniciação Científica e \\ Jornada de Transplantes de Órgãos.
}

\begin{abstract}
Orlando de Castro e Silva', Ana Carolina Delazia Albuquerque Santana ${ }^{I}$
${ }^{I}$ Chairman and Head of the Department of Surgery and Anatomy, Faculty of Medicine of Ribeirao Preto, University of Sao Paulo, Ribeirao Preto, Sao Paulo, Brazil and President of the Congress.

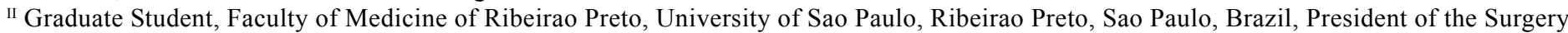
and Transplant League - Centro Acadêmico Rocha Lima (CARL) and member of academic organizing commission of the Congress
\end{abstract}

\section{The Events}

October 26, 2011 has arrived. After a year and a half of intensive preparations, the XII National Congress of Experimental Surgery, the IX Forum of Scientific Initiation in Clinical Surgery and Experimental Surgery, and the Multidisciplinary Workshop on Organ Transplantation will be held in Ribeirão Preto. We have elaborated a program whose central theme refers to the approach to the natural path of research in a surgical area, i.e., from the laboratory to clinical practice. The clinical applicability of a therapeutic procedure will be emphasized at the different round tables and conferences, showing its invariably experimental origin.

Over the last two decades, scientific and technological progress has expanded the limits of experimental investigation in order to provide new diagnostic and therapeutic options for man. This progress has required surgeons to refine their technical and scientific skills, ranging from knowledge of biochemistry, molecular biology etc. to knowledge and control of an enormous instrumental and technological machinery which has become increasingly microinstrumental as required by the new surgical options of recente years. In addition, the need has arisen for doctors, and surgeons in particular, to respect the ethics of the doctor-patient relationship in a rigorous manner in their actions in order not to let themselves move away from the patients in view of the diagnostic and therapeutic facilities provided by the advent of the new technologies.

Thus, many aspects will be discussed, ranging from molecular and cellular details to videolaparoscopy and robotic surgery, as well as the ethics of teaching and of patient care.

As part of this congress, the IX Forum of Scientific Initiation in Clinical Surgery and Experimental Surgery will be the link between what occurs in medical school in terms of research and teaching and medical performance, a corollary of academic knowledge. Based on the Teaching, Research and Extension triad, the objective of the forum is to offer the opportunity to undergraduate or graduate students of the entire scientific community of the country to show their scientific work. In addition, the forum intends to provide access to what is new in the academic environment to the public of the event , stimulating a discussion about the importance of scientific initiation for the training of students by developing their critical spirit and psychomotor skills and awakening their investigative spirit and interest in science, thus generating better prepared professionals with an expanded vision of the world ${ }^{1}$. Furthermore, other still polemic topics will be approached, such as the perspectives of experimental surgery and advanced general surgery, and the daily ethics of students which will interfere with their activity as physicians, i.e., relevant topics not only for the evolution of experimental surgery, but for the entire surgical and medical scientific community ${ }^{1}$.

Another event of the Congress will be the I Multidisciplinary Workshop of Organ Transplantation which will analyze the various facets of the complex process of organ transplantation, with emphasis on the role of both medical and nursing student leagues mainly in the dissemination of the importance of donation for the effective action of the entire transplantation process. Transplants will be viewed and extensively discussed from different angles by professionals in each health area, who have a specific, important and essential function in this process. This discussion will be essential for everybody to have a clear knowledge about these actions for a better efficiency and integration of all parties.

\section{The Supplement}

In this event we will be launching a supplement of Acta Cirúrgica Brasileira devoted to the publication of 25 full papers, almost all of them of an experimental nature, which have been submitted for presentation as posters at the Congress and also for appreciation for publication in Acta, the official organ of the Brazilian Society for the Development of Research in Surgery (SOBRADPEC) and the entity sponsoring this Congress. The papers came from various regions of Brazil and, when analyzed, were found to represent an important part of the investigations carried out in our country. 
The Supplement is a publication separate from the normal issues in series of a journal, authorized by its editor and contributing to the annual volume of the journal together with all other normal issues ${ }^{2,3,4}$. These full papers were evaluated by a publication committee with the usual rigor of Acta. The papers published in the supplement will have international visibility since Acta Cirúrgica Brasileira is indexed by Thomson Reuters (Former Institute for Scientific Infomation-ISI). This confers even greater responsibility and importance to the XII National Congress of Experimental Surgery.

This supplement is $\mathrm{n}^{\circ} 2$ of volume 26, 2011 of Acta Cirúrgica Brasileira, distributed in $\mathrm{CD}$ to all participants in the XII National Congress of Experimental Surgery, in the IX Forum of Scientific Initiation and in the Multidisciplinary Workshop on Organ Transplantation. In addition, the supplement will be accessed on line in www.scielo/acb.

On this scenario, we trust that this October Congress will be an event where the current state of modern surgery can be clearly exposed and discussed in the lectures and conferences proffered by renowned Brazilian surgeons and surgeons from other countries such as Spain, Hungary, Italy, Chile, and the United States.

Let us all join together in the light of Science, in the constant spring warmth of our city of Ribeirão Preto.

\section{References}

1. Santana A C D, Castro e Silva, O. Social Impact of Research in the University. Medicina (Ribeirão Preto) 2010,43: 455-8

2. Castro e Silva, O. Surgery from experimental research to clinical application and vice-versa. Acta Cir Bras. 2006, 21(suppl.1)1-2

3. Castro e Silva, O. Papers of the Postgraduation Program of the Department of Surgery and Anatomy of Ribeirão Preto Medical School, University of São Paulo, Brazil. Acta Cir.Bras.2008, 23 (suppl.1):1 4. Castro e Silva, O.VIII Fórum de Ribeirão. Um evento voltado aos acadêmicos de medicina, que continua sólido, já com ares de congresso. Acta Cir Bras.2001,16 (suppl.1)1-2 